\title{
EFFECT OF DENSITY ON GROWTH AND SURVIVAL OF YOUNG JUNE SUCKER
}

\author{
Mark C. Belk ${ }^{1}$ and R. Cary Tuckfield ${ }^{2}$
}

\begin{abstract}
One of the fundamental determinants of survival and growth of individuals is population density. Typically, individuals exhibit negative density dependence, but positive density dependence (Allee effect) may occur. Understanding patterns of density dependence is important for conservation and management of species that have low densities as a result of recent population declines. June sucker (Chasmistes liorus) is an endangered species that was formerly abundant but now is found at low densities in Utah Lake. We tested the hypothesis that young June sucker exhibit positive density dependence (i.e., Allee effects) in growth and survival at low densities. In addition, we tested the hypothesis that patterns of density dependence in growth and survival of young June sucker are consistent across years. We conducted a series of 5 experiments in 5 separate years. All 5 experiments included similar levels of density manipulations of young June sucker. June sucker exhibited Allee effects in both growth and survival in some years, but patterns of density dependence varied widely among years. Growth exhibited consistent patterns of negative density dependence, especially at higher densities. Survival was less affected by density, exhibiting no response to density in about half of the experimental comparisons. Overall, intermediate densities around 50 individuals $\cdot \mathrm{m}^{-2}$ seemed to provide the best tradeoff between growth and number produced.
\end{abstract}

RESUMEN.-Uno de los elementos fundamentales para la supervivencia y crecimiento de individuos es la densidad poblacional. Típicamente, los individuos muestran dependencia negativa a la densidad, pero la dependencia positiva a la densidad (el efecto Allee) puede ocurrir. El entendimiento de los patrones de dependencia a la densidad es importante para la conservación y el manejo de especies que tienen bajas densidades como resultado de una declinación reciente de la población. El Chasmistes liorus es una especie en peligro que anteriormente fue abundante, pero ahora se encuentra en densidades bajas en el lago Utah. Examinamos la hipótesis de que los Chasmistes liorus jóvenes muestran dependencia positiva a la densidad (es decir, efectos Allee) en crecimiento y sobrevivencia a densidades bajas. Además, examinamos la hipótesis de que los patrones de dependencia a la densidad en crecimiento y sobrevivencia del Chasmistes liorus joven son consistentes de un año a otro. Llevamos a cabo una serie de cinco experimentos durante cinco años distintos. Los cinco experimentos incluyeron niveles similares de manipulaciones de densidad del Chasmistes liorus. El Chasmistes liorus demostró efectos Allee tanto en crecimiento como en sobrevivencia durante algunos años, pero sus patrones de dependencia a la densidad variaron ampliamente de año en año. El crecimiento exhibió patrones consistentes de dependencia negativa a la densidad, especialmente en densidades más altas. La densidad afectó menos la supervivencia, sin exhibir respuesta a la densidad en aproximadamente la mitad de las comparaciones experimentales. En general, las densidades intermedias alrededor de 50 individuos $\cdot \mathrm{m}^{-2}$ parecieron proporcionar el equilibrio óptimo entre crecimiento y número producido.

One of the fundamental determinants of survival and growth of individuals is population density. The number of individuals in a given area determines resource abundance and access, and in large part, resource abundance determines individual performance. In the most straightforward sense, higher densities lead to lower per capita resource availability and lower growth and survival. Such a pattern is usually referred to as negative density dependence because the performance measure has a negative relationship to density (Stephens et al. 1999). However, not all species or populations follow the simple negative density-dependent pattern-2 other possibilities exist. Over some range of densities, performance may be inde- pendent of density. If densities are not high enough to decrease the per capita resource availability, then performance will not be affected. Lack of density dependence is expected only over some range of relatively low densities, followed by typical negative density dependence at higher densities. In addition to this plateau effect, some species or populations may show positive density dependence at low densities. This phenomenon, known as the Allee effect, creates a hump-shaped relationship between density and performance (Courchamp et al. 1999, Stephens et al. 1999).

The term Allee effect is used to describe patterns of positive density dependence; however, positive density dependence can arise from

\footnotetext{
${ }^{1}$ Department of Biology, Brigham Young University, Provo, UT. E-mail: mark_belk@byu.edu

2Savannah River Ecology Laboratory, Aiken, SC.
} 
3 quite different mechanisms. The most common mechanisms discussed in the literature are termed genetic Allee effects and demographic Allee effects. Genetic Allee effects refer to a reduction in fitness caused by inbreeding or genetic homogeneity at low population sizes. Demographic Allee effects refer to an increase in successful reproduction as the number of suitable mates increases in the local environment. A third mechanism, termed a component Allee effect, is an increase in some component of fitness with density because of an increase in social interactions or facilitation not necessarily related to finding a mate. For example, a decrease in foraging success and corresponding growth and production of offspring could be a consequence of low numbers of socially foraging individuals (Courchamp et al. 1999, Stephens and Sutherland 1999). Although genetic and demographic Allee effects have been explored quite thoroughly, component Allee effects have not been broadly incorporated in theoretical analyses or demonstrated empirically in many species (Courchamp et al. 1999). One further difference is that genetic and demographic Allee effects are expected to affect adult stages of any species at low population densities, whereas component Allee effects are expected at low densities only in species that exhibit social dependence in some component of fitness other than finding a mate. Thus, component Allee effects can arise during any life stage and in any component that affects fitness (e.g., juvenile growth and survival).

Resource availability fluctuates annually in many systems. During years of high resource abundance, effects of density may be muted compared to years with low resource availability. Thus, we might expect variation in the strength or pattern of density dependence among years. At low densities, fluctuations in resource levels may be relatively unimportant, whereas, at high densities, negative density dependence might always be expected even when resources are relatively abundant. At high densities, density-dependent effects overwhelm year-to-year variation in resource availability. Consequently, most of the variation in patterns of density dependence as a result of variation in resource availability will be observed at low population densities. Understanding the pattern of density dependence is especially important for species that are currently experiencing reduced population sizes compared to historical population sizes (Courchamp et al. 1999).
Conservation efforts to manipulate or augment reduced populations, either for control of invasive species or management of endangered and threatened species, depend on knowledge of density-dependent interactions at low densities. Previously abundant species that have been reduced in population size may be especially prone to Allee effects because of evolved social facilitation effects (Boukal et al. 2007). Some endangered species fit this pattern of former abundance, and it is these species that may be most likely to exhibit component Allee effects at low densities.

June sucker (Chasmistes liorus) is a large sucker endemic to Utah Lake, Utah. June sucker feed on zooplankton suspended in the water column and exhibit the typical morphological characteristics of lake suckers, such as large mouths and narrow lips, in contrast to benthicfeeding suckers, which have smaller mouths and wider lips (e.g., the closely related Utah sucker, Catostomus ardens; Whitney and Belk 2000, Belk et al. 2008). At one time, June sucker were extremely abundant in the lake, and great numbers were observed feeding in an apparently coordinated fashion (Billman 2008). So abundant were they, that during an 1889 visit to Utah Lake, David Starr Jordan suggested he could walk from his canoe to shore on the backs of the congregated suckers (Carter 1969). Habitat loss and degradation and introduction of nonnative species have reduced this large population to a small fraction of historic levels. Currently, June sucker is listed as an endangered species, and population size is estimated at a few hundred (Andersen et al 2007) to a few thousand individuals. Because of their former abundance and current low population densities, June sucker provide a model system to explore component Allee effects and patterns of density dependence in an endangered species.

In this study, we tested 2 hypotheses related to density-dependent effects on growth and survival of June sucker in its native environment. First, we tested the hypothesis that June sucker exhibit component Allee effects at low densities. Second, we tested the hypothesis that patterns of density dependence are consistent across years.

\section{Methods}

\section{Study Site and Experimental Protocol}

All experiments were conducted in or near the Provo Bay area of Utah Lake in central 
TABLE 1. Details of experimental design for each year. Both growth and survival were measured as response variables from each experiment. Number of replicates represents the number per treatment combination.

\begin{tabular}{llccc}
\hline Year & Treatments & $\begin{array}{c}\text { Levels of density } \\
\left(\text { fish } \cdot \mathrm{m}^{-2}\right)\end{array}$ & $\begin{array}{c}\text { Duration of experiment } \\
\text { (days) }\end{array}$ & Replicates \\
\hline 2002 & Density/time & $24,44,84,164$ & 22,35 & 2,3 \\
2004 & Density/vegetation & $24,48,120$ & 56 & 5 \\
2005 & Density/vegetation & $24,48,160$ & 70 & 5 \\
2006 & Density & $24,50,150$ & 56 & 5 \\
2008 & Density & $24,50,150$ & 63 & 5 \\
\hline
\end{tabular}

Utah. Provo Bay is a shallow bay that forms the southeastern extent of the lake. Utah Lake is one of the largest natural freshwater lakes in the western United States and is the only historic native location of the endangered June Sucker. Provo River, Spanish Fork River, and American Fork River are primary inflows, and Jordan River drains the lake north to the Great Salt Lake. The lake has a large surface area $(39,214 \mathrm{ha})$, but average depth is only $2.74 \mathrm{~m}$. Provo Bay, like the rest of the lake, is turbid with visibility averaging $<25 \mathrm{~cm}$ year-round.

To test for temporal variation in the form of density dependence, we conducted a series of 5 experiments in 5 separate years (2002-2008). All 5 experiments followed a similar protocol: larval suckers were introduced into cages (with consistent densities) in or near Provo Bay early in the growing season and were maintained until near the end of the growing season (or until water was depleted). At the end of the experiment, surviving individuals were counted and measured for growth. Details of each experimental design are found in Table 1.

In general, each year's experiment consisted of a replicated design with 3 levels of density. In 2002 only, there were 4 levels of density, and time in the experiment was also included as a replicated factor with 2 levels (22 and 35 days). In 2004 and 2005, there was an additional factor, simulated vegetation structure, crossed with density in a fully crossed factorial design. Although the question addressed in the overall series of studies (i.e., effects of density) does not include the effects of structure, we retained these replicates and this factor in the final analysis because they contained information on the effects of density that would allow greater precision for estimating least-squares means and resulting effect sizes.

Individuals were kept in replicate cages consisting of a plastic pipe $(\mathrm{PVC})$ frame $(1 \times 0.5$ $\times 1 \mathrm{~m}$ deep) covered with $1.5-\mathrm{mm}$-mesh PetProof ${ }^{\circledR}$ screen fabric during each experiment.
Screening was attached to the frame with a silicone adhesive, leaving the top of the cage open. Cages were placed on the substrate and anchored with two 1.8-m steel posts. Tops of each cage were covered with 4 -cm-mesh netting to exclude predators. The experimental array was arranged in rows, with a minimum distance of $2 \mathrm{~m}$ between all cages. When young June sucker were $6-8$ weeks old and in the postflexion mesolarva or metalarva stages of development (mid-July), they were transferred to Provo Bay from the Fisheries Experiment Station (FES) in Logan, Utah, where eggs had been hatched. Offspring from 3-4 different spawnings were combined to avoid family-specific responses. In mid-July, individuals were counted out according to densities and randomly assigned to cages. We photographed all individuals assigned to a given cage in a shallow tray with a scale to determine mean beginning size for each cage (in some years, we measured a subset of larvae and determined a common mean beginning size for all cages). Lengths were measured from digital photos using Sigma Scan ${ }^{\circledR}$ Pro software from Jandel Scientific. Cages were checked for damage weekly for the duration of the experiment.

The length of the experiment varied by year and availability of water (Table 1 ). To capture fish at the end of the experiment, cages were removed from the water and fish were collected from the cage. Fish were killed in a solution of MS-222 and placed in plastic bags labeled with treatment and cage number. Survival was calculated as the number of fish recovered from each cage divided by the number of fish that were placed in the cage at the beginning of the experiment. To calculate mean growth rate, mean standard length (SL) at the beginning of the experiment (measured from photos or a subset of individuals) was subtracted from mean SL measured for each cage at the end of the experiment. 


\section{Statistical Analysis}

To test the first hypothesis of potential Allee effects in young June sucker, we analyzed each experiment (year) separately as they were designed. Growth and survival were the response variables, and they were analyzed separately by year. Growth was not transformed because it conformed to assumptions of the model, but survival was logit-transformed (Ramsey and Schafer 2002). In 2002, the main effects were density (4 levels) and time in the experiment (2 levels), and the interaction was included. In 2004 and 2005, main effects were density (3 levels) and simulated structure (2 levels: present and absent), and the interaction was included. In 2006 and 2008, density was the only main effect (3 levels in both years). We used the method of linear contrasts to compare leastsquares (LS) means (Neter et al. 1996) for the density main effect in an ANOVA for each year's experiment. To test for Allee effects and pattern of density dependence, we evaluated a linear contrast between the least-squares means of low and medium levels of density-the latter minus the former. A second linear contrast was evaluated between the least-squares means for medium- and high-density levels - the former minus the latter. All data were analyzed using JMP ${ }^{\circledR} 7$ software from SAS Institute.

To evaluate the consistency of density dependence effects among years, we used the method known as meta-analysis (Gurevitch and Hedges 1993, Rosenberg et al. 2000, Gurevitch et al. 2001). We chose 2 measures of effect size (ES) to compare density-dependence effects across years: (1) the difference between 2 means scaled by the pooled standard deviation between them (Hedge's $d$ ) and (2) the logarithm of the ratio of 2 means $(\ln R)$. Because the sample size in our annual experiments differs among years and therefore affects the variance of these samples' statistics (Hedge's $d$ and $\ln R$ ), each term in the point estimate of the cumulative effect size (CES) should be weighted by the sampling variance of that statistic as

$$
C E S=\frac{\sum_{i=l}^{k} \omega_{i} E S_{i}}{\sum_{i=l}^{k} \omega_{i}},
$$

where $\omega_{i}=1 / v_{i}\left\{i=1,2, \ldots k^{\text {th }} E S\right\}$ and $v_{i}=$ sampling variance of the ES measure (Rosenberg et al. 2000). Effect sizes were separated into 2 groups for comparison of different parts of the density spectrum. Medium-low $(\mathbf{M}-\mathrm{L})$ density tests the pattern in the lower part of the spectrum, and medium-high $(\mathrm{M}-\mathrm{H})$ density tests the predominant pattern in the upper part of the density spectrum. If the overall pattern is negative density dependence, the $\mathrm{M}-\mathrm{L}$ comparison will be significantly negative (confidence interval will not overlap 0 ) and the $\mathrm{M}-\mathrm{H}$ comparison will be significantly positive. An Allee effect would be manifest by a significant positive outcome for both the $\mathrm{M}-\mathrm{L}$ and the $\mathrm{M}-\mathrm{H}$ comparisons. We are interested in the hypothesis that the CES $\neq 0$, and since each measure is approximately normally distributed for large sample sizes, we may calculate the upper and lower 95\% confidence limit (UCL95, LCL95) for each CES as

$$
\begin{gathered}
U C L_{95}=C E S+t_{\alpha=0.025, k-1}\left(s_{C E S}\right) \text { and } \\
L C L_{95}=C E S-t_{\alpha=0.025, k-1}\left(s_{C E S}\right),
\end{gathered}
$$

where $t_{\alpha=0.025, k-1}=2$-tailed $t$-distribution quantile with $k-1$ degrees of freedom, and $s=$ standard error of the CES statistic calculated as

$$
\sqrt{1 / \sum_{i=l}^{k} \omega_{i}}
$$

\section{Results}

\section{Individual Year Analyses}

Growth varied significantly among density levels for each year (Table 2). Significant positive density dependence in growth between the low and intermediate densities occurred in 2002 (Allee effect). Significant negative density dependence in growth between the low and intermediate densities occurred in 2004 and 2005. In 2006 and 2008, there was no difference in growth rate at low and medium densities (plateau effect). There was significant negative density dependence in growth between medium and high densities in all years (Table 3, Fig. 1).

Survival varied significantly among density levels in 2005 and marginally in 2002 and 2004 (Table 4). Significant positive density dependence in survival between the low and medium densities occurred in 2002. Significant negative density dependence in survival between the low and intermediate densities occurred in 2005. In 2004, 2006, and 2008, there was no difference in survival at low and medium densities (plateau 


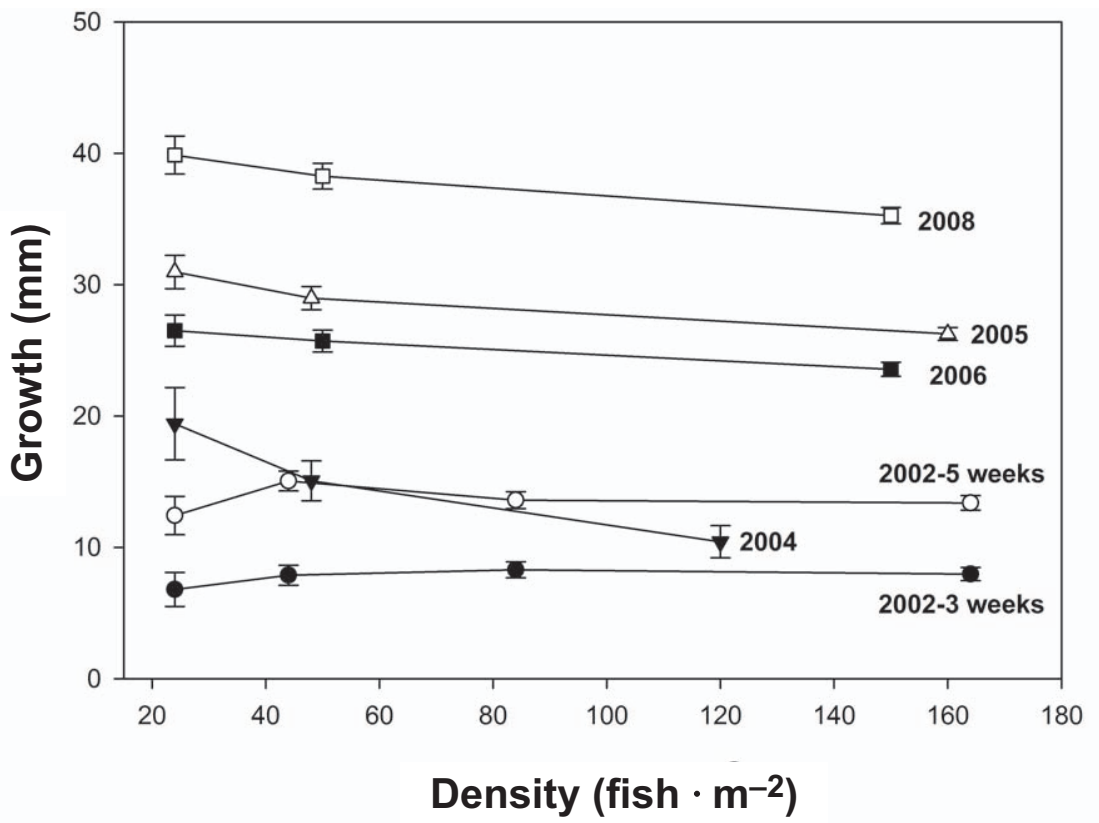

Fig. 1. Least-squares means of growth (in mm standard length) of juvenile June sucker during the first-year growing season at multiple densities in each of 5 years. Patterns of density dependence range from positive (Allee effects) to negative or neutral among years. Error bars represent one standard error around the mean.

TABLE 2. ANOVA table for growth for each year's experiment analyzed separately. In 2002, "days" refers to the number of days the experiment ran (i.e., 22 or 35 days). In 2004 and 2005, "structure" refers to presence or absence of simulated vegetative structure. Significant effects are bolded.

\begin{tabular}{|c|c|c|c|c|}
\hline Year & Source & df (num., denom.) & $F$ & $P$ \\
\hline 2002 & $\begin{array}{l}\text { days } \\
\text { density } \\
\text { days } \times \text { density }\end{array}$ & $\begin{array}{l}\mathbf{1}, 385 \\
3,385 \\
3,385\end{array}$ & $\begin{array}{r}33.6 \\
1.5 \\
2.9\end{array}$ & $\begin{array}{c}<0.0001 \\
0.21 \\
\mathbf{0 . 0 3}\end{array}$ \\
\hline 2004 & $\begin{array}{l}\text { density } \\
\text { structure } \\
\text { structure } \times \text { density }\end{array}$ & $\begin{array}{l}2,162 \\
1,162 \\
2,162\end{array}$ & $\begin{array}{r}26.7 \\
27.4 \\
5.6\end{array}$ & $\begin{array}{c}<0.0001 \\
<0.0001 \\
0.004\end{array}$ \\
\hline 2005 & $\begin{array}{l}\text { density } \\
\text { structure } \\
\text { structure } \times \text { density }\end{array}$ & $\begin{array}{l}2,695 \\
1,695 \\
2,695\end{array}$ & $\begin{array}{r}23.7 \\
8.1 \\
4.0\end{array}$ & $\begin{array}{c}<0.0001 \\
0.004 \\
0.019\end{array}$ \\
\hline 2006 & density & 2,368 & 16.3 & $<0.0001$ \\
\hline 2008 & density & 2,234 & 25.2 & $<0.0001$ \\
\hline
\end{tabular}

TABLE 3. Probability values (and direction of the relationship) associated with independent contrasts comparing low to medium and medium to high density levels for both growth and survival. Significant values are bolded.

\begin{tabular}{|c|c|c|c|c|}
\hline \multirow[b]{2}{*}{ Year } & \multicolumn{2}{|c|}{ Growth } & \multicolumn{2}{|c|}{ Survival } \\
\hline & Low to medium & Medium to high & Low to medium & Medium to high \\
\hline 2002 & $0.0009(+)$ & $0.016(-)$ & $0.017(+)$ & $0.025(-)$ \\
\hline 2004 & $<0.0001(-)$ & $0.0034(-)$ & 0.1 & $0.019(-)$ \\
\hline 2005 & $0.016(-)$ & $<0.0001(-)$ & $0.015(-)$ & $0.038(+)$ \\
\hline 2006 & 0.28 & $<0.0001(-)$ & 0.75 & 0.09 \\
\hline 2008 & 0.06 & $<0.0001(-)$ & 0.67 & 0.92 \\
\hline
\end{tabular}




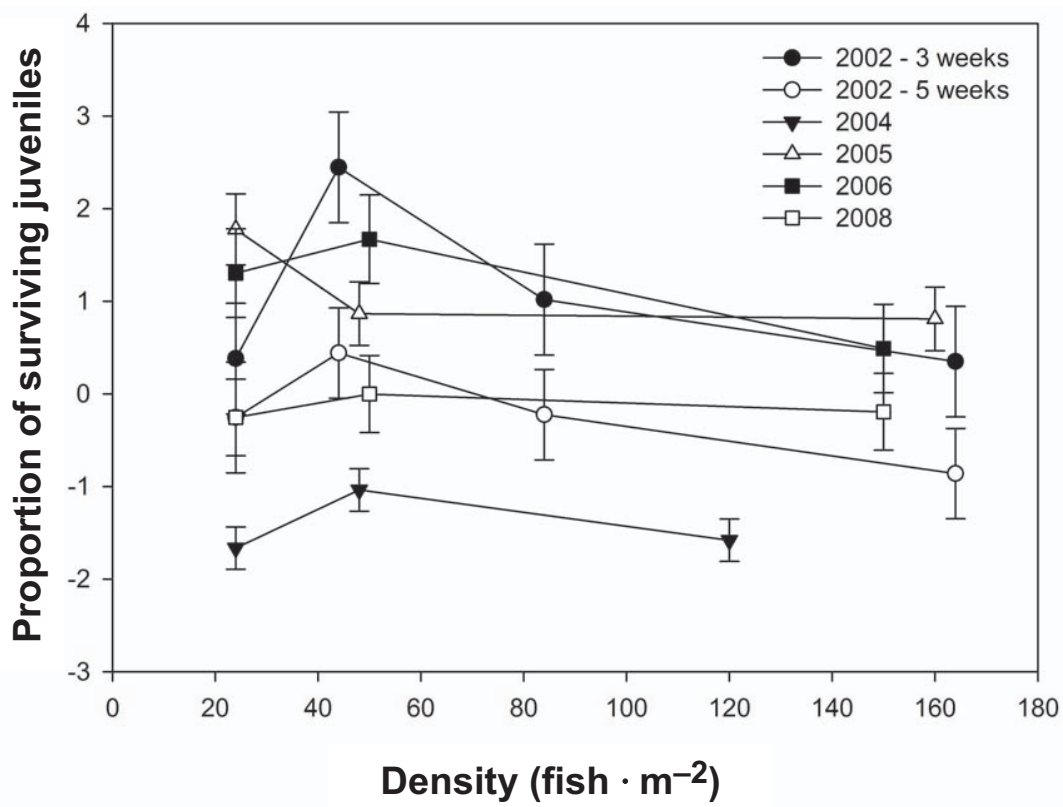

Fig. 2. Least-squares means and $95 \%$ confidence intervals of proportion of surviving juvenile June sucker during the first-year growing season at multiple densities in each of 5 years. Patterns of density dependence range from positive (Allee effects) to negative or neutral among years.

TABLE 4. ANOVA table for survival for each year's experiment analyzed separately. In 2002, "days" refers to the number of days the experiment ran (i.e., 22 or 35 days). In 2004 and 2005, "structure" refers to presence or absence of simulated vegetative structure. Significant effects are bolded.

\begin{tabular}{llccc}
\hline Year & Source & $\mathrm{df}($ num., denom. $)$ & $F$ & $P$ \\
\hline 2002 & days & $\mathbf{1 , 1 2}$ & $\mathbf{1 0 . 1 8}$ & $\mathbf{0 . 0 0 8}$ \\
& density & 3,12 & 3.2 & 0.06 \\
\multirow{2}{*}{2004} & days $\times$ density & 3,12 & 0.15 & 0.9 \\
& density & 2,24 & 3.24 & 0.056 \\
& structure & 1,24 & 0.0 & 0.98 \\
2005 & structure $\times$ density & 2,24 & 1.5 & 0.25 \\
& density & $\mathbf{2 , 2 4}$ & $\mathbf{3 . 8}$ & $\mathbf{0 . 0 3 7}$ \\
& structure & $\mathbf{1 , 2 4}$ & $\mathbf{2 2 . 0}$ & $<\mathbf{0 . 0 0 0 1}$ \\
2006 & structure $\times$ density & $\mathbf{2 , 2 4}$ & $\mathbf{3 . 4}$ & $\mathbf{0 . 0 5}$ \\
& density & 2,12 & 1.9 & 0.2 \\
& density & 2,12 & 0.1 & 0.9 \\
\hline
\end{tabular}

effect). There was significant negative density dependence in survival between medium and high densities in 2002 and 2004. In 2005, there was significant positive density dependence in survival between medium and high densities, and in 2006 and 2008, there was no difference in survival at medium and high densities (plateau effect; Table 3, Fig. 2).

\section{Meta-Analysis}

Values for the M-L comparison for growth are significantly negative for both effect-size statistics, indicating an overall trend of negative density dependence for growth at lower densities. Similarly, values for the $\mathrm{M}-\mathrm{H}$ comparison for growth are significantly positive for both effect-size statistics, indicating an overall trend of negative density dependence for growth at higher densities. Values for the $\mathrm{M}-\mathrm{L}$ comparison for survival are no different from zero, indicating an overall trend of a plateau effect (no relation to density) for survival at lower densities. In contrast, values for the $\mathrm{M}-\mathrm{H}$ comparison for survival are significantly 


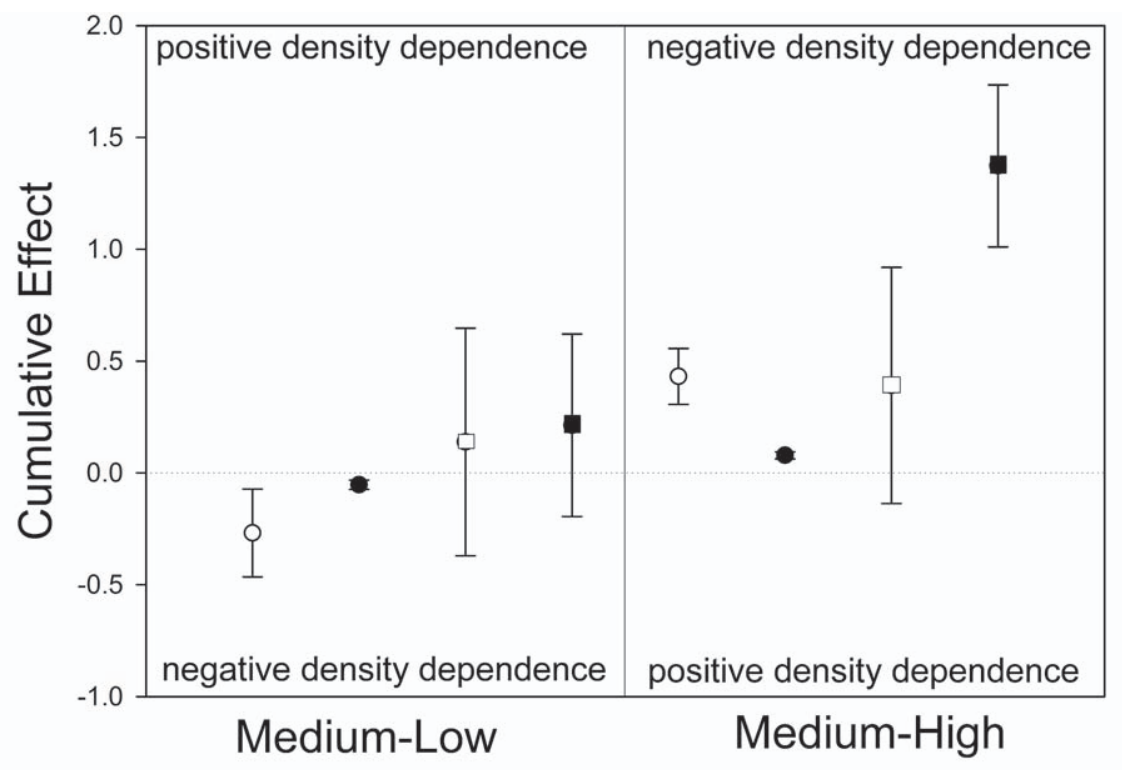

Fig. 3. Mean and 95\% confidence intervals of survival and growth for 2 effect-size measures for cumulative effect over all 5 years of experiments. Two comparisons were made for each variable: medium-density minus low-density values and medium-density minus high-density values. Growth is indicated by circles and survival is indicated by squares. Open symbols represent Hedge's $d$, and filled symbols represent $\ln R$.

positive or no different from zero, depending on the effect-size statistic, indicating an overall trend of negative density dependence or a plateau effect for survival at higher densities (Fig. 3).

\section{DisCUSSION}

Allee Effects in June Sucker

June sucker exhibit Allee effects in growth and survival in some years. The Allee effect is manifest as a decrease in per capita fitness of a population when numbers fall below some threshold (Stephens et al. 1999). Three classes of Allee effects are generally recognized: those caused by genetic inbreeding or homogeneity, those caused by demographic stochasticity, and those caused by reduced cooperative interactions of conspecifics (Courchamp et al. 1999, Stephens and Sutherland 1999). Allee effects resulting from genetic or demographic factors have been described for many taxonomic groups (Fowler and Baker 1991) and have been the focus of recent theoretical and empirical studies (Amarasekare 2004, Brown et al. 2004, Henle et al. 2004). In contrast, Allee effects resulting from reduced cooperative interactions at low densities remain sparsely documented and comparatively unexplored (Courchamp et al. 1999, Stephens et al. 1999, Frank and Brickman 2001). This category of Allee effect, where some component of overall fitness (e.g., growth survival, reproduction, etc.) is lowered by reduced cooperative interactions of conspecifics at low densities, has been termed a "component Allee effect" (Stephens et al. 1999).

In June sucker, component Allee effects may have been unimportant historically because of large population size. However, population declines, driven by changes in habitat and environment, may expose previously masked component Allee effects. Like many endangered species, the June sucker has experienced recent extreme reductions in population size, which appear to have resulted in some years in expression of a component Allee effect that reduces growth and survival. The data in this study apply to juvenile June sucker, and it is not clear if the same patterns of density dependence exist among older age classes. Adult June sucker have been observed feeding in an aggregated pattern (Billman 2008), but whether or not this results in some form of positive density dependence is unknown. Even for juvenile June sucker, the mechanism that leads to the observed component Allee effects is not clear. 
Variation Among Years in Pattern of Density Dependence

The pattern of density dependence among years is surprisingly variable. All of the possible forms of density dependence (neutral, positive, and negative) were observed among years in this series of experiments. Understanding what factors determine the pattern of density dependence is important both for management of populations and for predicting effects of environmental change (Cianelli et al. 2004). The growth response was more consistent in pattern among years than the survival response. At higher densities, growth was consistently negatively density dependent. In contrast, survival exhibited highly variable and nonsignificant relationships to density across the range tested. Growth appears to be a sensitive indicator of density-mediated resource availability, whereas survival during the first-year growing season is not a good indicator of resource availability. Variation in juvenile growth can have strong effects on later life stages. Overwinter mortality of teleost fishes in seasonal systems is strongly size-dependent, with larger individuals (i.e., those experiencing more rapid growth rate during the first-year growing season) exhibiting better survival (Sogard 1997, Sogard and Olla 2000). Thus, a negative effect of density on juvenile growth is translated into an effect on first-year survival. Overwinter mortality can be extremely high and may outweigh the mortality experienced during the first growing season (Sogard 1997).

Given that the effect of density on both growth and survival was stronger at the $\mathrm{M}-\mathrm{H}$ level rather than the $\mathrm{M}-\mathrm{L}$ levels (Table 4), these patterns suggest overall that intermediate densities (i.e., about 50 individuals $\cdot \mathrm{m}^{-2}$ ) may provide the best tradeoff between growth and number of suckers produced in a given area. Low densities (i.e., about 25 individuals • $\mathrm{m}^{-2}$ ) may provide higher growth or lower growth (depending on the year), but survival is likely to be the same as or poorer than at intermediate densities. High densities (i.e., $>100$ individuals $\cdot \mathrm{m}^{-2}$ ) provide many smallbodied individuals, but they are unlikely to overwinter successfully. The largest number of high-quality juveniles will likely result from intermediate densities. Stocking densities and densities in large cages for grow-out purposes should be geared toward these intermediate densities.

\section{ACKNOWLEDGMENTS}

This research was supported by Brigham Young University (BYU) and grants from the Utah Division of Wildlife Resources and was approved by the June Sucker Recovery Implementation Program and the BYU Institutional Animal Care and Use Committee. Preliminary analysis of data from 2002 was included previously in a master's thesis by David Gonzalez (BYU). Numerous undergraduate volunteers from BYU contributed to both field and laboratory work.

\section{Literature Cited}

Amarasekare, P. 2004. Spatial dynamics of mutualistic interactions. Journal of Animal Ecology 73:128-142.

Andersen, M.E., C.J. Keleher, J.E. Rasmussen, E.S. HanSEn, P.D. Thompson, D.W. Speas, M.D. Routledge, AND T.N. HEDRICK. 2007. Status of June sucker in Utah Lake and refuges. Pages 39-58 in M.J. Brouder and J.A. Scheurer, editors, Status, distribution, and conservation of native freshwater fishes of western North America: a symposium proceedings. American Fisheries Society, Bethesda, MD.

Belk, M.C., L.J. Benson, J. Rasmussen, and S.L. Peck. 2008. Hatchery-induced morphological variation in an endangered fish: a challenge for hatchery-based recovery efforts. Canadian Journal of Fisheries and Aquatic Sciences 65:401-408.

Billman, E.J. 2008. Observations of shoaling and feeding behavior of June sucker, Chasmistes liorus, in a refuge population. Western North American Naturalist 68: 390-395.

Boukal, D.S., M.W. Sabelis, and L. Berec. 2007. How predator functional responses and Allee effects in prey affect the paradox of enrichment and population collapses. Theoretical Population Biology 72:136-147.

Brown, D.H., H. Ferris, S.L. Fu, and R. Plant. 2004 Modeling direct positive feedback between predators and prey. Theoretical Population Biology 65: 143-152.

CARTER, R.D. 1969. A history of commercial fishing on Utah Lake. Master's thesis, Brigham Young University, Provo, UT.

Ciannelli, L., K.-S. Chan, K.M. Bailey, and N.C. StenSETH. 2004. Nonadditive effects of the environment on the survival of a large marine fish population. Ecology 85:3418-3427.

Courchamp, F., T. Clutton-Brock, and B. Grenfell. 1999. Inverse density dependence and the Allee effect. Trends in Ecology and Evolution 14:405-410.

Fowler, C.W., AND J.D. BAKER. 1991. A review of animal population dynamics at extremely reduced population levels. Report of the International Whaling Commission 41:545-554.

Frank, K.T., and D. Brickman. 2001. Contemporary management issues confronting fisheries science. Journal of Sea Research 45:173-187.

Gurevitch, J., P.S. CurTis, And M.H. Jones. 2001. Metaanalysis in ecology. Advances in Ecological Research 32:199-247. 
Gurevitch, J., And L.V. Hedges. 1993. Meta-analysis: combining the results of independent experiments Pages 378-398 in S.M. Scheiner and J. Gurevitch, editors, Design and analysis of ecological experiments. Chapman \& Hall, New York, NY.

Henle, K., S. Sarke, And K. Wiegand. 2004. The role of density regulation in extinction processes and population viability analysis. Biodiversity and Conservation 13:9-52

Neter, J., M.H. Kutner, C.J. Nachtsheim, and W. Wasserman. 1996. Applied linear statistical models. 4th edition. WCB/McGraw-Hill, Boston, MA.

Ramsey, F.L., AND D.W. Schafer. 2002. The statistical sleuth: a course in methods of data analysis. 2nd edition. Duxbury Press, Albany, NY.

RosenberG, M.S., D.C. Adams, And J. Gurevitch. 2000 MetaWin: statistical software for meta-analysis, version 2. Sinauer Associates, Inc., Sunderland, MA.

SoGARD, S.M. 1997. Size-selective mortality in the juvenile stage of teleost fishes: a review. Bulletin of Marine Science 60:1129-1157.
Sogard, S.M., AND B.L. OLla. 2000. Endurance of simulated winter conditions by age-0 walleye pollock: effects of body size, water temperature and energy stores. Journal of Fish Biology 56:1-21.

Stephens, P.A. AND W.J. SutherLand. 1999. Consequences of the Allee effect for behaviour, ecology, and conservation. Trends in Ecology and Evolution 14: 401-405.

Stephens, P.A., W.J. Sutherland, and R.P. Freckleton. 1999. What is the Allee effect? Oikos 87:185-190.

Whitney, M., AND M.C. BELK. 2000. Threatened fishes of the world: Chasmistes liorus Jordan, 1878 (Catostomidae). Environmental Biology of Fishes 57:362.

Received 23 February 2011

Accepted 26 May 2011 